\title{
Quantitative Analysis of Irigenin in the Different Species of Iris Plant by RP- HPLC and its Efficacy Against Different Plant Pathogens
}

\author{
Sajad Hassan Wani ${ }^{1 *}$, Hilal Ahmad Bhat ${ }^{1}$, Javid Iqbal Mir ${ }^{1}$, Shahid Ali Akbar ${ }^{2}$, Sajad Un Nabi ${ }^{3}$, Desh Beer Singh ${ }^{4}$, \\ Nazeer Ahmad ${ }^{5}$
}

\section{Sajad Hassan Wani ${ }^{1 *}$, Hilal Ahmad Bhat ${ }^{1}$, Javid lqbal Mir', Shahid Ali Akbar'2, Sajad un $\mathrm{Nabi}^{3}$, Desh Beer Singh ${ }^{4}$, Nazeer Ahmad ${ }^{5}$}

\section{'Biotechnology division, Central Institute of Temperate Horticulture- ICAR, Srinagar, Jammu and Kashmir, INDIA. \\ ${ }^{2}$ Entomology division, Central Institute of Temperate Horticulture- ICAR, Sri- nagar, Jammu and Kashmir, INDIA. ${ }^{3}$ Plant Pathology, Central Institute of Temperate Horticulture-ICAR, Srinagar, Jammu and Kashmir, INDIA. \\ ${ }^{4}$ Central Institute of Temperate Horticulture- ICAR, Srinagar, Jammu and Kashmir, INDIA. \\ ${ }^{5}$ Sheri Kashmir University of \\ Agriculture Science and Technology Kashmir (SKUAST-K), Jammu, Jammu and Kashmir, INDIA. \\ Correspondence \\ Sajad H Wani}

Biotechnology division, Central Institute of Temperate Horticulture- ICAR, Srinagar, Jammu and Kashmir, INDIA.

Phone No: 09697824317

E-mail: sajadhassaniiim@gmail.com

\section{History}

- Submission Date: 22-10-2017

- Review completed: 08-11-17;

- Accepted Date: 14-11-2017

DOI : 10.5530/pj.2017.6s.153

Article Available online http://www.phcogj.com/v9/i6s

\section{Copyright}

(C) 2017 Phcog.Net. This is an openaccess article distributed under the terms of the Creative Commons Attribution 4.0 International license.

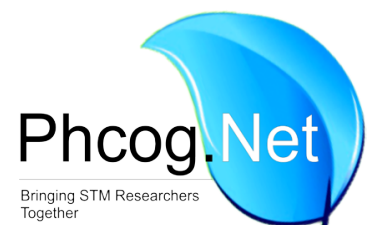

\begin{abstract}
Irigenin belongs to family of isoflavonoids, isolated from Iris Plant of Kashmir Himalaya. A rapid and specific reverse phase high pressure chromatography (RP HPLC) method for quantitative analysis of irigenin in the different species of Iris Plant was developed. The samples were analyzed on RP-C 18 e column (chromolith, $5 \mu \mathrm{m}, 4.6 \times 100 \mathrm{~mm}$ ). The HPLC system was operated at ambient temperature $( \pm 30 \mathrm{c})$. The mobile phase consisted of methanol: water. The detecting wavelength at $260 \mathrm{~nm}$ and flow rate of $0.6 \mathrm{ml} / \mathrm{min}$. The standard irigenin was diluted using the mobile phase at a known concentration of $1 \mathrm{mg} / \mathrm{ml}$; the sample was filtered through sample filter of $0.45 \mu$ pore size. The filtrate was introduced on to a reverse phase analytical column. The content of irigenin in the different species of Iris Plant was determined. The HPLC showed an excellent performance in separating the irigenin in different species of Iris Plant. Furthermore, the antipathogenic activity. The test compound at each respective concentration was found to be statistically superior against scab. Furthermore, the test compound @ 5000 ppm proved significantly most effective by providing (82.49\%) inhibition in the mycelia growth of apple scab. It was followed by fusarium (77.27\%) at 5000 ppm. Lowest reduction in mycelia growth $(65.78 \%)$ was recorded in marssonina and did not differ significantly from Alternaria $(67.47 \%)$ at $5000 \mathrm{ppm}$. Furthermore, lowest inhibition of mycelia growth was recorded at 1000 ppm. Similar trend was recorded for rest of the pathogens i.e. highest reduction at 5000 ppm, lowest at 1000 ppm and at 2000, 3000 and 4000 ppm it ranges between the first two but increases with increase in concentration. From this study irigenin is potent compound which can be used for controlling the growth of respective pathogens.

Key words: Iris Plant, Irigenin, RP-HPLC, Bio efficacy.
\end{abstract}

\section{INTRODUCTION}

Plants are important reservoir of natural products that have got tremendous biological potential. During the last few years the focus is more on Plant secondary metabolites and extracts due to their various pharmacological activities. ${ }^{1,2,3}$ The plant products are now a days more widely used worldwide. The focus is on promoting the use of plant based products and to develop useful and reliable methods for quality control of these products and formulations to certify their safety and efficacy. ${ }^{4,5}$ There should be official documentation that particular analytical method can provide reliable and reproducible data. ${ }^{6}$ The genus Iris, which belongs to family iridaceae is cosmopolitan in distribution. ${ }^{7}$ The phytochemistry of the genus reveals that it is richest source of flavonoids, isoflavonoids, quinines and benzoquinones. ${ }^{8}$ The three major compounds of the plant are iridin, irigenin and tectorigenin.

Isoflavones and their glycosides are the most important flavonoid compounds isolated from the genus Iris. In most reports they were found in the rhizomes,

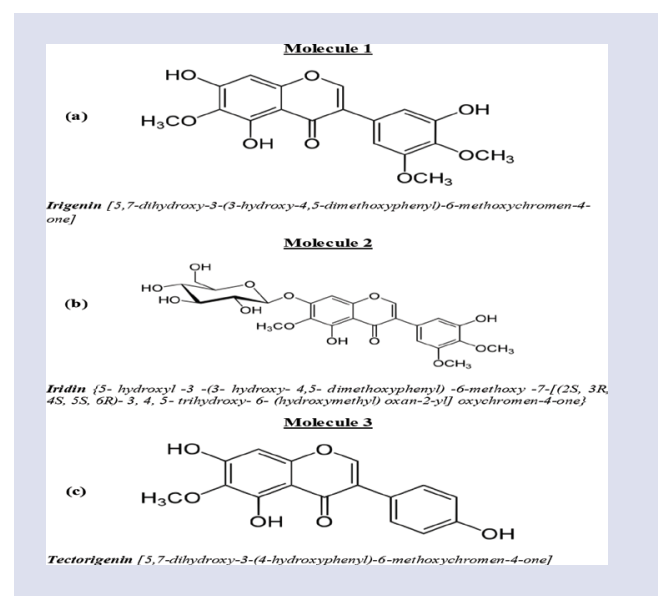

rare in the flowers and leaves. irigenin an isoflavone from the rhizomes of Iris Plant shows a wide variety of biological activities. Tectorigenin shows antioxidant ${ }^{1}$, antimicrobiotic $^{4}$, Most of the saccharides found in isoflavone glycosides reported are monosaccharides
Cite this article: Wani SH, Bhat HA, Mir JI, Akbar SA, Nabi Su, Singh DB, Ahmad N. Quantitative Analysis of Irigenin in the different Species of Iris Plant by RP- HPLC and its Efficacy against different Plant Pathogens. Pharmacog J. 2017;9(6)Suppl:s23-s27. 
or disaccharides. The monosaccharides are normally -D- glucopyranosides ( $-\mathrm{D}-\mathrm{Gl} c \mathrm{p}$ ), and similarly, the disaccharides are mainly -D-Glcp-(1 6)- -D-Glcp. They usually form $O$-glycosides, with the sugar moiety often linked to C-7 or C-4' position of the known aglycones. Among the new isoflavone glycosides isolated from the genus Iris during the reporting period, there are five containing monosaccharides, nine containing disaccharides and one containing trisaccharides. ${ }^{9,10,11,12,13}$ Generally, the control of plant diseases is well established with synthetic fungicides. ${ }^{14}$ Especially apple growers usually adopt a zero tolerance policy towards management of diseases. ${ }^{15}$ Furthermore, the inappropriate and increased use of fungicides. ${ }^{16}$ Has resulted in fungal resistance ${ }^{17}$ and ecological imbalance. ${ }^{18}$ To reduce the dependence on synthetic fungicides the main aim of our research is to develop alternative eco-friendly management strategies depending on plant based bioactive compound Irigenin.

\section{MATERIAL AND METHODS}

Chemicals, Reagents and Materials Methanol (Chromatographic grade, Jiangsu Hanbon Sci and Tech. Co., Ltd.), , $\mathrm{H}_{2} \mathrm{O}$ (HPLC grade, sigma chemicals), Irigenin (Sigma, St. Louis) used as an external standard (marker compound). The Iris Plant species was collected from the different ecozones of Kashmir.

\section{Chromatographic analysis}

Chromatographic analysis was carried out by Kromasil $100 \mathrm{C}_{18} \mathrm{v}$ reversed phase column $(250 \times 4.6 \mathrm{~mm})$ packed with $5 \mu \mathrm{m}$ diameter particles. The mobile phase was methanol: water. The mobile phase was filtered through a $0.45 \mu$ membrane filter. Then deaerated ultrasonically prior to use. RP-HPLC separation of standard Irigenin at $262 \mathrm{~nm}$. Flow rate and injection volume were $0.6 \mathrm{ml} / \mathrm{min}$ and $5 \mu \mathrm{l}$. The Chromatographic peaks of the extracts were confirmed by comparing their Retention time with those of the reference standards. Irigenin was carried out by the integration of the peak using external standard method. All chromatographic operations were carried out at ambient temperature.

\section{Preparation of Standard Solution}

About $1 \mathrm{mg}$ of given irigenin sample was accurately weighed and dissolved in $1 \mathrm{ml}$ mobile phase. Then standard solution was filtered with $0.2 \mu \mathrm{m}$ membrane filter paper with sample filter.

\section{Sample Solution}

Five species of Iris Plant were collected from the different ecozones of Kashmir. The plant material was shade dried and then grinded into a fine powdered material. The methanol extract was prepared and the extracts were kept at-20c. The $5 \mathrm{mg} / \mathrm{ml}$ of the extract were dissolved and passed through $0.2 \mu \mathrm{m}$ filter paper and submitted to chromatographic analysis. During sample preparation extracts were heated at low temperature to avoid breaking of heat labile molecules. The HPLC were performed for each extract and each extract were compared with the standard.

\section{Bioevaluation}

The bioactive compound (iriginen) isolated from Iris sp. was evaluated (in vitro) at five different concentrations (1000, 2000, 3000, 4000 and 5000 ppm) against Venturia inaequalis, Alternaria mali, and Marssonina caronaria causal agents of apple scab, Alternaria leaf spot of apple and marssonina leaf blotch of apple, respectively. Furthermore, it was also evaluated against Fusarium oxysporium causal agent of saffron corm rot at same five concentrations. To evaluate the efficacy of irigenin against various fungi standard Phytopathological technique i.e. poisoned food technique of was adopted. ${ }^{19}$
Fifty milliliters of basal medium (PDA) was poured in $250 \mathrm{ml}$ conical flask, plugged with non-absorbent cotton and autoclaves at $15 \mathrm{lbs}$ per square inch pressure. After semi cooling the medium, $50 \mathrm{ml}$ of iriginen of double concentration than the desired one was incorporated in each flask except check. Media from each flask was transferred sterilized Petri plates under aseptic conditions. Each treatment was replicated four times in completely randomized design (CRD) and inoculated with $3 \mathrm{~mm}$ diameter mycelia disc taken from 7 days old culture in case of Alternaria mali and Fusarium oxysporium. However, in case of Venturia inaequalis and Marssonina caronaria 40 days old culture was used and, then incubated at desired temperature for respective fungi. The relative efficacy of different treatments was ascertained by taking the radial mycelia growth inhibition of fungi over control was calculated by using the formula of Vincentn. $^{20}$

Were,

$\mathrm{C}=$ Mycelial growth in check

$\mathrm{T}=$ Mycelial growth in treatment

\section{Structure of Irigenin}<smiles>COc1c(O)ccc(-c2cc(=O)c3c(O)c(OC)c(O)cc3o2)c1OC</smiles>

\section{RESULTS}

\section{Quantitative analysis of Irigenin by Reverse Phase High} Pressure Liquid Chromatography (RP-HPLC) in different species of Iris Plant.

The quantitative analysis of, irigenin in the 12 different samples of Iris Plant species were carried out by using reverse phase high pressure liquid chromatography. The Stock solutions of extracts and the standard were obtained by dissolving $5 \mathrm{mg}$ of each of the extract in $1.0 \mathrm{ml} \mathrm{MeOH}$ and $1.0 \mathrm{mg}$ of the standard in $1.0 \mathrm{ml} \mathrm{MeOH}$ respectively. The resulting solutions were filtered through $0.45 \mu \mathrm{m}$ filter membrane. Working solutions of appropriate concentrations were prepared by diluting stock solutions. The stability of stock as well as working solutions was monitored and no change in concentration was observed. The optimization of HPLC conditions was performed using the standard solution of, irigenin first and then solution of IC-3 sample. Peak resolutions were tested and compared using different solvent systems (acetonitrile-methanol, acetonitrile-water, and methanol-water) in varying proportions. The separation of, irigenin was achieved on a RP-18e column using methanolwater $(30: 70 ; \mathrm{v} / \mathrm{v})$ at a flow rate of $0.6 \mathrm{ml} / \mathrm{min}$ with a runtime of $55 \mathrm{~min}$. Photodiode array detector (DAD) was used in HPLC analysis and the optimum monitor wavelength at $265 \mathrm{~nm}$ was selected from the full range spectra. Methanol stock solution of the standard reference compound, irigenin was prepared and diluted to appropriate concentrations for the construction of calibration curve. At least four concentrations of, irigenin were injected in the concentration range of $0.08 \mu \mathrm{g} / \mathrm{ml}$ to $0.96 \mu \mathrm{g} / \mu \mathrm{l}$. The calibration curve was constructed by plotting the peak area versus the concentration of each analyte with detector wavelength set at $265 \mathrm{~nm}$. Excellent calibration curve was obtained for the standard within the concentration range of $0.08 \mu \mathrm{g}$ to $0.96 \mu \mathrm{g} / \mu \mathrm{l}\left(\mathrm{r}^{2}=\right.$ curve coefficients $>0.998$ ). The recovery study was within the concentration range of the calibration curve. The recovery of the method was estimated by spiking IK-1 sample with $2.0 \mu \mathrm{g} / 3.8 \mathrm{mg}$ of the standard irigenin. The data from the recovery studies revealed that the recovery of the method was in the 
range of 98.2 to $101.2 \%$ evaluating the accuracy of the method., irigenin was separated in all the samples using the developed HPLC method. Typical chromatograms of the different extracts and the mixed standard are shown in Figure 1, respectively. The identification of the investigated compound was carried out by comparison of retention times and UV spectra with those obtained by injecting standards in the same conditions. The developed HPLC method was applied to analyze, Irigenin in twelve samples of five species of Iris. The data are summarized in Table 1, 2. The results showed that the content of, Irigenin greatly varied in five different Iris species. Furthermore, the content of, Irigenin varied within species growing at different eco-geographical zones. The concentration Irigenin ranged from $1.06 \%$ dry weight in IC -1 sample to $7.84 \%$ dry weight in IG-2 sample.

\section{Antipathogenic activity}

Analysis of the data revealed that the bioactive compound Irigenin significantly inhibit the mycelia growth of all the test fungi as compared to check, and showed progressive reduction in mycelia growth as the respective concentrations increased Table. The compound irigenin differ significantly in its efficacy against the funji under study. Irrespective of the concentrations, the test compound exhibited maximum mean growth inhibition of (55.05\%) against scab. It was followed by (50.08\%) and $(41.12 \%)$ against fusarium and Alternaria, which were significant different from one another. However, the test compound proved to be the least effective in per cent mycelia growth inhibition (39.37\%) against marssonina but did not differ significantly from Alternaria.

The test compound at each respective concentration was found to be statistically superior against scab. Furthermore, the test compound @ $5000 \mathrm{ppm}$ proved significant most effective by providing (82.49\%) inhibition in the mycelia growth of scab. It was followed by significantly different fusarium $(77.27 \%)$ at $5000 \mathrm{ppm}$. Lowest reduction in mycelia growth $(65.78 \%)$ was recorded in marssonina and did not differ significantly from Alternaria (67.47\%) at 5000 ppm. Furthermore, lowest inhibition of mycelia growth was recorded at $1000 \mathrm{ppm}$. Similar trend was recorded for rest of the pathogens i.e. highest reduction at $5000 \mathrm{ppm}$, lowest at 1000 ppm and at 2000, 3000 and 4000 ppm it ranges between the first two but increases with increase in concentration. A significant relationship was observed to exist between the test compound and concentration. Irrespective of fungi, the inhibitory effect of test compound increased significantly with increase in concentration from 20.52 per cent at $1000 \mathrm{ppm}$ to 73.25 per cent at $5000 \mathrm{ppm}$. The corre- sponding inhibition at 2000, 3000 and 4000 ppm concentration were noticed to be $32.85,46.51$ and 58.89 per cent, respectively.

\section{DISCUSSION}

The HPLC is a unique, versatile, universal and well recognized tool for qualitative and quantitative evaluation of herbal products against their respective bioactive molecules in terms of quality and batch-to-batch reproducibility. ${ }^{21,22}$ The present study reveals the distribution of irigenin in the different Iris Plant species growing at different altitudes of Kashmir valley. The results showed the highest concentration of irigenin in iris germanica and lowest in iris croceae. The extracts from different species showed the presence of irigenin by RP-HPLC method developed in our laboratory. The results of screening of irigenin in the different species of Iris Plant revealed that iris germanica and iris kashmiriana contain the highest level of this isoflavones, the results indicate that these plant species are the richest source of irigenin, especially in the Iris Plant species growing in the Kashmir (india). The developed RP- HPLC method for the determination of irigenin is easy and sensitive and will be used in further research. Furthermore, there is tremendous pressure on fungicides for the management of diseases especially in apple.

\begin{tabular}{cccc} 
Table 1: Collection of samples of Iris plant species & \\
\hline Code & Samples & Sources & $\begin{array}{c}\text { Collection } \\
\text { date }\end{array}$ \\
\hline IC-1 & Iris croceae & Sonamarg, Kashmir, India & May, 2016 \\
IC-2 & Iris croceae & Shopian, Kashmir, India & April, 2016 \\
IC-3 & Iris croceae & Gulmarg, Kashmir, India & June, 2016 \\
IE-1 & Iris ensata & Naranag, Kashmir, India & May, 2016 \\
IE-2 & Iris ensata & Shopian, Kashmir, India & April, 2016 \\
IG-1 & Iris germanica & CITH field, Srinagar, Kashmir, India & April, 2016 \\
IG-2 & Iris germanica & Gulmarg, Kashmir, India & June, 2016 \\
IG-3 & Iris germanica & Sonamarg, Kashmir, India & May, 2016 \\
IK-1 & Iris & Local graveyard, Srinagar, Kashmir & April, 2016 \\
& kashmiriana & India & \\
IK-2 & Iris & Naranag, Kashmir, India & May, 2016 \\
& kashmiriana & Gulmarg, Kashmir, India & June, 2016 \\
IS-1 & Iris spuria & Sonamarg, Kashmir, India & May, 2016 \\
IS-2 & Iris spuria & &
\end{tabular}

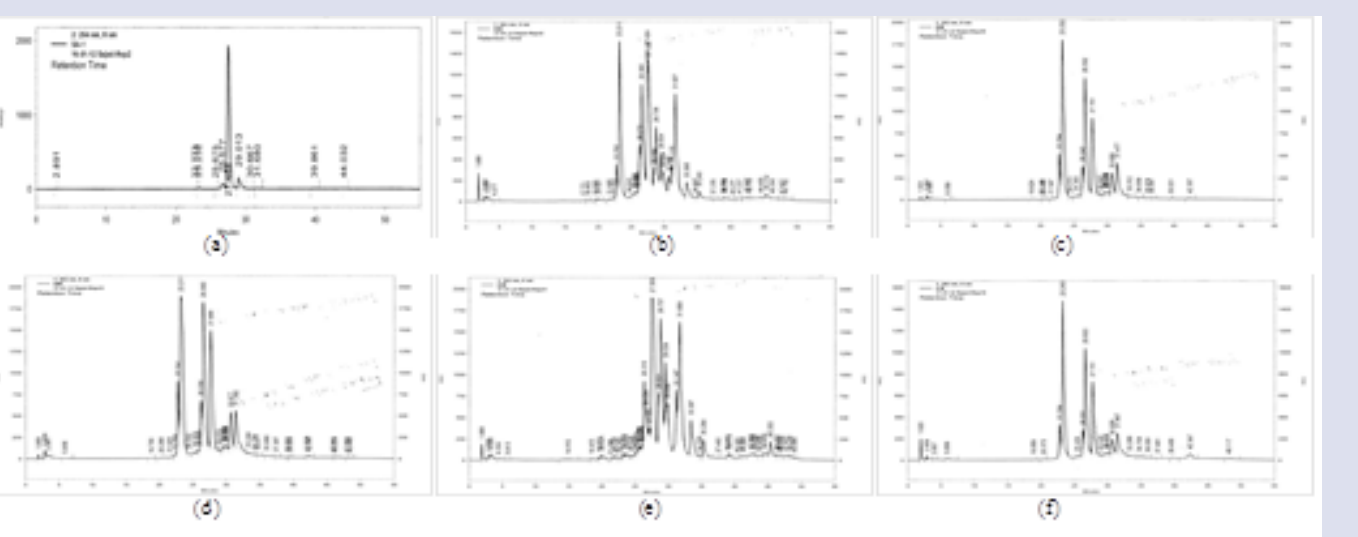

Figure 1: Quantification of Irigenin in various Iris sp. by RP-HPLC: Typical HPLC chromatograms for quantification of Irigenin (a) Irigenin marker (b) Iris kashmiriana (c) Iris ensata (d) Iris spuria (e) Iris germanica (f) Iris croceae 
Table 2: In vitro Efficacy of Bioactive Compound Irigenin in Inhabiting Mycelia Growth of Various Fungi

\begin{tabular}{ccccccc}
\hline \multirow{2}{*}{$\begin{array}{c}\text { Concentration (ppm) } \\
\text { Disease }\end{array}$} & \multicolumn{6}{c}{ Mycelial growth inhibition over check (\%)* } \\
\cline { 2 - 7 } & 1000 & 2000 & 3000 & 4000 & 5000 & Mean \\
\hline Scab & $28.87(33.13)$ & $43.47(41.20)$ & $54.57(48.87)$ & $65.85(54.23)$ & $82.49(65.27)$ & $55.05(48.54)$ \\
& & & & & & \\
Fusarium & $14.85(22.83)$ & $26.29(31.17)$ & $42.16(40.47)$ & $54.81(47.73)$ & $67.47(55.20)$ & $41.12(39.48)$ \\
Alternaria & $24.09(29.34)$ & $35.85(36.75)$ & $50.38(44.34)$ & $62.81(50.59)$ & $77.27(61.52)$ & $50.08(44.50)$ \\
Marssonina & $14.25(21.94)$ & $25.80(30.50)$ & $38.94(38.59)$ & $52.10(46.18)$ & $65.78(54.18)$ & $39.37(38.27)$ \\
Mean & $20.52(26.81)$ & $32.85(34.90)$ & $46.51(43.06)$ & $58.89(49.68)$ & $73.25(59.04)$ & - \\
\hline
\end{tabular}

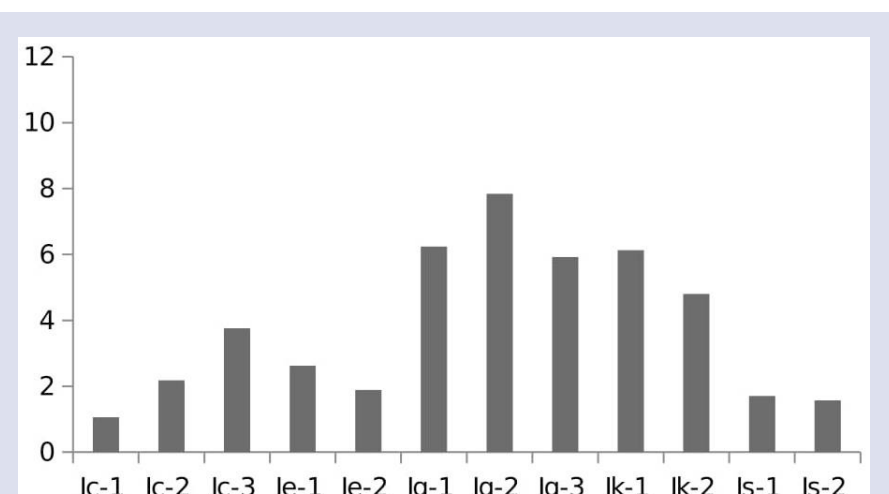

Figure 2: Percentage content of irigenin in the different species of Iris plant collected from different ecogeographical regions of kashmir.

Inappropriate use of synthetic fungicides has resulted in eco-logical imbalance, health issues and resistance. ${ }^{23}$ So, the number of fungicidal sprays and their dosage is to be increased for the management of the diseases. Furthermore, the number of fungicidal groups are limited in number. So, to reduce the load of fungicides, there are alternative eco-friendly management strategies, and among those use of plant based extract and molecules is one. Plants contain thousands of constituents that are valuable source of new and biologically active molecules possessing antimicrobial property. ${ }^{24}$ There is tremendous potential of Irigenin (isolated from iris spp.) for the management of fungal diseases. As the plant is easily available, has got higher diversity, and its corms are available thought the year. Furthermore, as a rule higher accumulation of bioactive compounds takes place in underground parts of plant compared to above ground. ${ }^{24}$ This bioactive compound will help in devising the new path for the management of diseases which will help in sustainable production especially in apple.

\section{CONCLUSION}

The method is simple, rapid, easy and precise. The demonstration was good at isocratic conditions. The method can be used for routine quantification of irigenin in the different plant extracts as well as in formulations. Furthermore, the compound was found potent against different pathogens that effect the economic crops of Kashmir.

\section{ACKNOWLEDGMENT}

The authors are thankful to SERB-DST for providing the financial assistance in the form of N-PDF/000500/LS and ICAR-CITH Srinagar for providing the infrastructural facilities to carry out the work.

\section{CONFLICT OF INTEREST}

The authors declare none conflict of interest.

\section{ABBREVIATION USED}

RP-HPLC: Reverse phase high pressure liquid chromatography; UV: Ultraviolet; ppm: parts per million; DAD: Diode array detector.

\section{REFERENCES}

1. Blumenthal M. The ABC clinical guide to herbs. New York: Thieme. 2003.

2. Bruneton J. Pharmacognosy, phytochemistry, medicinal plants. Paris: Intercept Ltd. 1999;2:545.

3. Loziene K, Venskutonis PR, Sipailiene A, Labokas J. Radical scavenging and antibacterial properties of the extracts from different Thymus pulegioides L. chemotypes. Food Chem. 2007;103(2):546-59.

4. Ministério da Saúde, Agência Nacional de Vigilância Sanitária (ANVISA), Brasil; Decreto $n^{\circ}$. 5813, de 22 de junho de 2006, aprova a Política Nacional de Plantas Medicinais e Fitoterápicos e dá outras providências,http://portal.saude.gov.br/ portal/arquivos/pdf/Decreto_N_5813.pdf , accessed 2009.

5. WHO; Quality control methods for medicinal plant materials, World Health Organization: Geneva. 1998

6. Ribani M, Bottoli CBG, Collins CH, Jardim ICFS, Melo LFC. Quim Nova. 2004;27:771.

7. Wilsom CA. Subgeneric classification in Iris re-examined using chloroplast sequence data Taxon. 2001;60(1):27-35

8. Rahman AU, Nasim S, Biag I, Jalil S, Orhan I, Sener B, et al. Anti-inflammatory isoflavonoids from the rhizomes of Iris germanica. J Ethnopharmacol. 2003;86(2):177-80.

9. Baytop T, Türkiye'de Bitkilerle Tedavi. Istanbul Universitesi, Eczacilik Fakültesi Yayinlari No.40: Sanal Matbaacilik, 1984

10. Choudhary MI, Nur-e-Alam M, Baig I. Four new flavones and a new isoflavone from Iris bungei. J Nat Prod. 2001;64(7):857-60.

11. Harborne JB. Plant Flavonoids in Biology and Medicine II: bio- chemical cellular and medicinal properties, Alan R Liss. Inc New York, 1988.

12. Rahman AU, Nasim S, Baig I, Orhan I, Sener B, Ayanoglu F, et al. Isoflavonoid Glycosides from the Rhizomes of Iris germanica Helvetica Chimica Acta. 2003;86(10):3354-62.

13. Iwashina T, Otani S. Flavonoids of the Genus /ris. Structures, Distribution and Function (Review). Ann Tsukuba Bot Gard.1998;17:147-83.

14. Pretty J. Agricultural sustainability: concepts, principles and evidence. Philosophical Transactions of the Royal Society B: Biological Sciences. 2008;363(1491):447-65.

15. Percival GC, Boyle S. Evaluation of microcapsule trunk injections for the control of apple scab and powdery mildew. Ann Applied Biology. 2005;147(1):119-27.

16. Genet JL, Jaworska G, Deparis F. Effect of dose rate and mixtures of fungicides on selection for Qol resistance in populations of Plasmopara viticola. Pest management science. 2006;62(2):188-94.

17. Haouala R, Hawala S, EIA-yeb A, Khanfir R, Boughanmi N. Aqueous and organic extracts of Trigonella foenum-graecum inhibit the mycelia growth of fungi. Journal of Environmental Sciences. 2008;20(12):1453-7.

18. Pramila-Tripathi, Dubey NK. Exploitation of natural products as an alternative strategy to control postharvest fungal rotting of fruit and vegetables. Postharvest biology and technology. 2004;32(3):235-45

19. Nene $Y L$, Thapliyal PN. Fungicides in plant disease control. Oxford and IBH publication, New Delhi, India. 1982;3:691.

20. Vincent JM. Distribution of fungal hyphae in the presence of certain inhibitors 
Nature. 1947;159(4051):850.

21. Nama S, Awen BZ, Chandu B, Kagga M. Development and validation of RP-HPLC method for the determination of riluzole hydrochloride in bulk and tablet dosage forms. Inter J Pharm Biomed Res. 2011;2:17-21.

22. Pandit S, Kumar M, Ponnusankar S, Pal BC, Mukherjee PK. RP-HPLC-DAD for simultaneous estimation of mahanine and mahanimbine in Murraya koenigii.
Biomed Chromatography. 2011;25(9):959-62

23. Rodino S, Butu M, Petrache P, Butu A, Cornea CP. Antifungal activity of four plants against Alternaria Alternate.2014;2285-1372.

24. Gurjar MS, Ali S, Akhtar M, Singh KS. Efficacy of plant extracts in plant disease management. 2012;3(3):425-33.

\section{GRAPHICAL ABSTRACT}

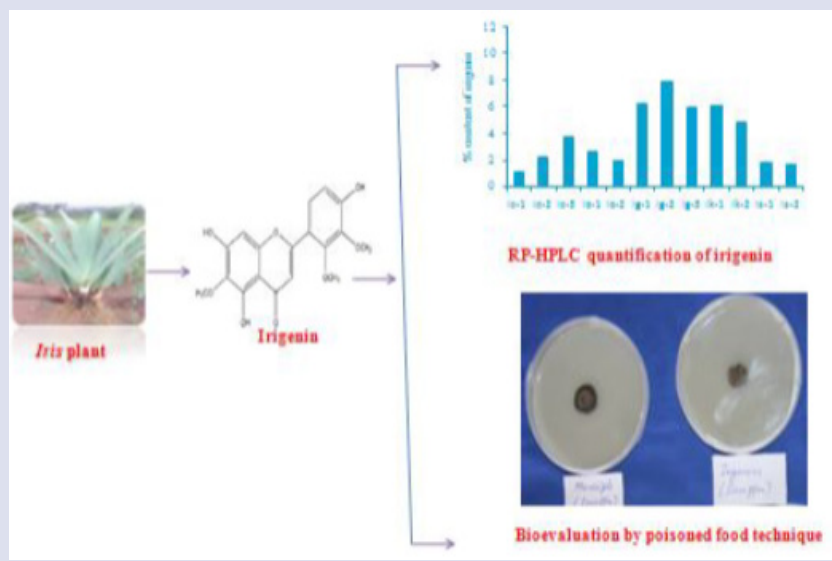

SUMMARY

- Iris plant belonging to family iridaceae is the richest source of secondary metabolites that two of Flavonoids and isoflavonoids.

- HPLC is a versatile technique in order to quantify the different constituents in different herbal preparations.

- Irigenin belonging to isoflavanoid class of compounds has been in 12 different species of Iris plant collected from different regions of Kashmir Himalaya.

- The content of irigenin was found greatly variant even in the same species collected from different eco-geographical regions of the valley.

- The content of irigenin was found highest in iris Germanica and lowest in Iris croceae.

- Bioevaluation studies reveal that the compound is potent in limiting the growth of different pathogens in a dose dependent manner. The efficacy was highest against apple scab.

- From this study it is clear that Iris plant extracts can be used in near future to get eco-friendly control of different plant diseases for sustainable agriculture production.

\section{ABOUT AUTHORS}

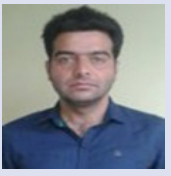

Sajad HWani: N- PDF(SERB/DST), Biotechnology Division, Central Institute of Temperate Horticulture, SrinagarICAR.

Hilal Ahmad Bhat: Senior Research Fellow, Biotechnology Division, Central Institute of Temperate Horticulture, Srinagar-ICAR.

Javid Iqbal Mir: Scientist plant biotechnology, Biotechnology Division, Central Institute of Temperate Horticulture, Srinagar-ICAR

Shahid Ali Akbar: N- PDF(SERB/DST), Entomology Division, Central Institute of Temperate Horticulture, Srinagar-ICAR.

Sajad Un Nabi: Scientist plant pathology, Plant Pathology Division, Central Institute of Temperate Horticulture, Srinagar-ICAR.

Desh Beer Singh: Director, Central Institute of Temperate Horticulture, Srinagar-ICAR.

Nazeer Ahmad: Vice - chancellor, Sheri Kashmir University of Agriculture Science and Technology Kashmir (SKUAST-K).

Cite this article: Wani SH, Bhat HA, Mir JI, Akbar SA, Nabi Su, Singh DB, Ahmad N. Quantitative Analysis of Irigenin in the different Species of Iris Plant by RP- HPLC and its Efficacy against different Plant Pathogens. Pharmacog J. 2017;9(6)Suppl:s23-s27. 